\title{
Erratum to: Communication Intervention to Teach Requesting Through Aided AAC for Two Learners With Rett Syndrome
}

\author{
Jessica Simacek $^{1}$ • Joe Reichle ${ }^{1}$ • Jennifer J. McComas ${ }^{1}$
}

Published online: 6 February 2016

(C) Springer Science+Business Media New York 2016

\section{Erratum to: J Dev Phys Disabil \\ DOI 10.1007/s10882-015-9423-7}

In the original published version of this article potential conflict of interest was not noted. This omission does not have implications to the method, results, or implications of the original published study. Potential conflict of interest is reported below.

\section{Conflict of Interest}

The authors have no potential conflict of interest, either direct or indirect, to report.

The online version of the original article can be found at http://dx.doi.org/10.1007/s10882-015-9423-7.

Jessica Simacek

sima0034@umn.edu

1 Department of Educational Psychology, University of Minnesota, 56 East River Road, Minneapolis, MN 55455, USA 